\title{
As premissas da organização do trabalho escolar e o projeto político-pedagógico de duas instituições privadas de educação básica: aproximações, distanciamentos e problematizações
}

\author{
The Premises of the organization of school work and the political pedagogical \\ project of two private institutions of basic education: approaches, distancing \\ and problematizations \\ Clara Rimolo Anele ${ }^{l}$ \\ Merlinde Piening Kohl ${ }^{2}$
}

\begin{abstract}
RESUMO
Neste artigo, o objetivo é, a partir da leitura do texto de Thurler e Maulini (2012), traçar um paralelo entre as ideias estruturantes dos autores e os projetos político-pedagógicos de duas escolas privadas de educação básica, buscando aproximações, distanciamentos e problematizando os conceitos selecionados. Foram selecionados os seguintes conceitos para esta análise: organização escolar, missão e metas; os princípios e as diretrizes pedagógicas; função do professor e a gestão de classe; o papel do educando; tradição e inovação. A partir das aproximações conceituais aos elementos extraídos pelos projetos político-pedagógicos das instituições analisadas, percebe-se fortalezas e fragilidades nos preceitos existentes nos documentos, o que permite uma leitura documental diferenciada, que aproxima as diretrizes institucionais do trabalho escolar desenvolvido.
\end{abstract}

Palavras-chave: Projeto político-pedagógico; Educação Básica; Gestão escolar.

\begin{abstract}
In this article, the objective is, from the reading of the text of Thurler and Maulini (2012), to draw a parallel between the structuring ideas of the authors and the political-pedagogical projects of two private schools of basic education, seeking approximations, distancing and problematizing the selected concepts. The following concepts were selected for this analysis: school organization, mission, and goals; pedagogical principles and guidelines; teacher function and class management; the role of the learner; tradition and innovation. From the conceptual approximations to the elements extracted by the political-pedagogical projects of the analyzed institutions, strengths and weaknesses were perceived in the precepts in the documents, allowing a differentiated documentary reading, which approximates the institutional guidelines of the work developed by those schools.
\end{abstract}

Keywords: Political-pedagogical project; Basic education; School management.

\footnotetext{
${ }^{1}$ Mestranda em Gestão Educacional pela Universidade do Vale do Rio dos Sinos - Unisinos. Coordenadora de Gestão de Pessoas dos Colégios e Unidades Sociais da Rede Marista - RS. clara.anele@icloud.com

${ }^{2}$ Mestranda em Gestão Educacional pela Universidade do Vale do Rio dos Sinos - Unisinos. Coordenadora Pedagógica do Colégio Sinodal de São Leopoldo (RS) e docente no IFPLA (Instituto de Formação de Professores de Língua Alemã, Ivoti-RS). merlinde@ sinodal.com.br
} 
Os autores Thurler e Maulini (2012) apresentam um panorama empírico sobre o trabalho escolar para "compreender e conceitualizar as relações entre a organização do ensino e as forças que podem orientar ou contrariar sua evolução". Os autores mostram a importância da organização escolar para que a aprendizagem ocorra. Eles comentam que a organização é

Simultaneamente, a ordem e a mu-
dança, o princípio ativo que man-
tém e transforma a dinâmica das in-
terações: é a parte do trabalho que
permite o trabalho, que o fecha em
si mesmo, que o torna autônomo,
mas também o limita em suas ambi-
ções. (THURLER; MAULINI,
2012, p.12)

Os autores referem que a meta, a intenção de qualquer organização escolar, é a luta contra o fracasso escolar. Eles pretendem levar o leitor a questionar a organização do trabalho para que se tenha uma evolução, pois o que os levantamentos internacionais revelam sobre a aprendizagem escolar é a de que há ainda grande fracasso escolar, contra o qual se luta. Segundo os autores, os alunos têm saído da escola sem terem adquirido os saberes necessários para viver dignamente, para conseguir um emprego, para conhecer seus deveres e exercer seus direitos, e o que é pior, segundo eles, os sistemas de ensino pouco têm se importado com esse cenário, com essa "exclusão". Quando nos deparamos com essas questões, pensamos muito no objetivo central de uma instituição educacional: a aprendizagem dos alunos em todas as suas dimensões - cog- nitiva, pragmática, social, emocional, organizacional, pessoal. Queremos que os alunos tenham a oportunidade de desenvolver seu potencial e suas habilidades e competências para poderem participar ativamente, de forma ética, dos contextos sociais dos quais fazem parte, que se constituam como sujeitos protagonistas. Questionamos sobre a forma como esse trabalho vem sendo organizado, conduzido e realizado. O trabalho organizacional da instituição de ensino está condensado no Projeto Político Pedagógico, também considerado um conjunto de princípios e de regras e deve contar, segundo Cury (2018), com a participação dos profissionais da educação, ou seja, ser elaborado de forma coletiva pelo corpo docente, liderado pelo gestor responsável" (CURY, 2018). O autor afirma que a comunidade educacional deve estar capacitada para levar a termo, de forma dialogal e participativa, o projeto pedagógico de qualidade da qual nasçam cidadãos ativos participantes da sociedade como profissionais compromissados.

O desejo de analisar os Projetos Político Pedagógicos de duas instituições confessionais privadas de educação básica é, além de verificar de que forma se assemelham quanto à organização do trabalho pedagógico, também investigar a forma como atendem ao ordenamento legal na oferta de qualidade educacional. Após a leitura do texto de Thurler e Maulini (2012), observamos que há pontos descritos que se assemelham aos Projetos Pedagógicos das duas escolas privadas de educação básica escolhidas para o tra- 
balho. Iniciemos com a organização das instituições, sua missão e suas metas.

\section{Problematização dos conceitos selecionados. Organização escolar, missão e metas}

Tanto o PEBM (Projeto Educativo do Brasil Marista) como o PPP (Projeto Político Pedagógico) do Centro de Ensino Médio Sinodal, as redes a que pertencem as instituições analisadas, trazem fortemente fundamentada a questão da organização escolar. Thurler e Maulini (2012, p.11) reportam a organização "como uma forma herdada, ancorada na história, nas leis, nos muros e nos móveis dos estabelecimentos" e complementam “[...] é também um processo, uma ação, um trabalho, que consiste em empregar racionalmente meios para obter um resultado". Os autores ainda afirmam que

Para quem e além das metas, é preciso ter meios, recursos, ideias e competências que permitam conduzir melhor as aprendizagens, regulálas de forma diferente, de maneira mais fina, melhor direcionada, hierarquizando os objetivos e variando, se necessário, as progressões. (THURLER; MAULINI, 2012, p.14)

O PEBM é referencial para os processos educativos, para a estrutura organizacional e para a gestão das escolas. Compreende além das considerações iniciais, história e contextualizações, a descrição de quatro dimensões: 1) Dimensão contextual - con- textos e trajetórias do instituto marista; 2) Dimensão conceitual - delineamentos e posicionamentos; 3) Dimensão operacional - as políticas institucionais nas ações; 4) Dimensão avaliativa - processos, diálogos e contextos. O PEBM é "orientador de políticas e práticas educacionais e instrumento didático pedagógica, pois se constitui num artefato de formação de sujeitos da educação marista" (UMBRASIL, 2010, p.15).

Segundo PEBM (UMBRASIL, 2010, p.56):

\footnotetext{
O Projeto reconhece e acolhe a pluralidade de identidades do sujeito, criança ao jovem, considerando que são sujeitos inteiros, diversos e diferentes que se relacionam com o mundo, com os conhecimentos e saberes a partir de sua inteireza e sua singularidade.
}

Na educação, a formação compreende as diferentes dimensões da pessoa: física e estética; afetiva; cognitiva; comunitária e social; éticovalorativa; e transcendente (TEIXEIRA, 2004). E é nesse contexto em que se insere a educação marista, em que

o jeito de educar fundamenta-se em uma formação integral. Investe na observação, na investigação, na reflexão, na abertura à realidade, no posicionamento crítico, na negociação, no protagonismo, em atitudes solidárias, no respeito e no cuidado com a natureza, na compreensão e na significação do mundo [...]. (UMBRASIL, 2009, p.43)

O Projeto Educativo do Brasil Marista apresenta que: 
O sujeito não é. Torna-se o que é nas tramas das relações de poder, nas relações sociais, das enunciações, dos discursos filosóficos, psicológicos, psicanalíticos, pedagógicos, antropológicos, sociológicos e teológicos que atravessam e inundam o cotidiano e que subjetivam modos reconhecidos de ser homem e mulher, criança e jovem, considerando a pluralidade de discursos identitário, de papéis sociais e culturais nos mais variados contextos nos quais se situa e se forma, estando sempre incompleto e inacabado, em constante processo de constituir-se, em devir. (UMBRASIL, 2010, p. 56).

O PEBM fundamenta e orienta a busca por novas e criativas formas de educar, evangelizar e defender os direitos de crianças e jovens. Na prática, o papel é de buscar consolidar e provocar a interação entre pessoas, processos e ações, tendo em vista uma melhor atualização e efetivação da missão marista (UMBRASIL, 2010).

Também o Centro de Ensino Médio Sinodal tem sua organização quanto à missão e às metas claramente definida. É um dos estabelecimentos de ensino associados à Rede Sinodal de Educação ${ }^{1}$, que se define como uma associação de escolas com origem nas comunidades da IECLB e cuja história

\footnotetext{
${ }^{1}$ A Rede Sinodal de Educação é o órgão responsável, na IECLB, pelo setor educacional escolar e universitário, prestando serviço às escolas vinculadas com Comunidades ou $\mathrm{Pa}$ róquias Evangélicas. Ela é integrada por todas as 53 escolas filiadas e sua Assembleia Geral é o foro máximo de deliberação. A Rede coordena as atividades em comum das instituições sinodais na área de aperfeiçoamento profissional de professores e outros profissionais da escola, teatro escolar, música, esportes e formação de lideranças. Além disso, presta assessoria técnico-pedagógica e administrativa aos estabelecimentos de ensino. http://redesinodal.com.br/portalrede/a-redesinodal/
}

remonta a 1935. A Rede Sinodal de Educação é uma entidade que visa, pelo trabalho conjunto, a auxiliar suas associadas na oferta de um ensino diferenciado, reconhecido pelas comunidades nas quais estão inseridas. A tarefa de cada um dos estabelecimentos de ensino é de buscar "o desenvolvimento do senso crítico, da criatividade e da integridade da pessoa, na dimensão de sua vocação para servir". Assim, o Colégio Sinodal sempre foi uma escola de referência em termos de qualidade. Seu objetivo básico é contribuir para formar as novas gerações para todos os setores de atividade humana, formar homens cultos com inteligência criadora e qualidades éticas e morais para irradiar os benefícios que aprenderam no meio em que atuarem. O Centro de Ensino Médio Sinodal contribui para formar indivíduos que tenham uma participação construtiva na sociedade tanto no presente, como cidadãos mirins e juvenis, quanto, e, principalmente, no futuro, como cidadãos emancipados (CENTRO DE ENSINO MÉDIO SINODAL, 2012).

Pode-se perceber que, assim como os autores no texto demonstram preocupação com a verdadeira aprendizagem e formação dos sujeitos a partir de uma organização que permita a interação e o desenvolvimento integral, também os PPPs das duas instituições de ensino mostram claramente esses mesmos objetivos, essas metas.

\section{Os Princípios e as Diretrizes Pedagógicas}

O Projeto Educativo do Brasil Marista, considerando a missão institucional e as demandas advindas do 
contexto contemporâneo, orienta-se pelos seguintes princípios: educação de qualidade como direito fundamental; ética cristã e busca do sentido da vida; solidariedade na perspectiva da alteridade e da cultura da paz; educação integral e construção das subjetividades. A Educação Marista:

É comprometida com o percurso da formação humana e da evangelização como centro do processo educativo que visa à formação cristã e cidadã, mediante o cultivo da justiça social, da solidariedade, da responsabilidade, da ética e do protagonismo na construção de uma humanidade nova. (UMBRASIL, 2010, p. 52).

Para concretizar o PEBM, o currículo precisa atender às diferentes dimensões da formação humana. Deve contemplar uma educação de qualidade, inovadora e competente. Deve expressar o protagonismo dos estudantes, dos docentes e dos gestores como sujeitos que constroem de forma cooperativa novos conhecimentos. Deve ser comprometido com os valores cristãos na prática do dia a dia.

Os princípios e as diretrizes do Centro de Ensino Médio Sinodal procuram ser coerentes com os valores estéticos, políticos e éticos que inspiram a Constituição e a LDBEN (1996), organizados sob três eixos: sensibilidade, igualdade e identidade. O princípio da estética da sensibilidade se expressa no espaço escolar, educando as pessoas para transformar o uso do tempo livre em atividade produtiva e criadora, a) integrando alegria e senso de humor; b) reconhecendo e valori- zando a diversidade da cultura regional e nacional, acolhendo a diversidade expressiva dos saberes escolares; c) considerando os conteúdos de aprendizagem como produção de sentidos e significados, conforme podemos ler no PPP do Centro de Ensino Médio. A política da igualdade se concretiza a partir de "condutas de participação e solidariedade, respeito e senso de responsabilidade, pelo outro e pelo público". (DCN, CNE/CEB no. 4/98 e 15/98). E quanto à ética da identidade, pode-se dizer que o maior objetivo é o desenvolvimento da autonomia, ancorada em conhecimentos e competências intelectuais que deem condições de realização de um projeto de vida (CENTRO DE ENSINO MÉDIO SINODAL, 2012).

\section{Os Processos de Ensino e de Aprendizagem}

Quanto aos processos de ensino e de aprendizagem, poderíamos dizer que a maneira como compreendemos o processo de aprendizagem é que determinará o tipo de ensino que teremos. Thurler e Maulini (2012, p. 24), quando falam da relação entre a aprendizagem e o ensino, afirmam que "na escola, é preciso trabalhar para aprender, mas a organização dos saberes e das atividades não são forçosamente superpostas". No PPP do Centro de Ensino Médio Sinodal (2012, p. 23), consta que:

\footnotetext{
Quando falamos em construção, apropriação e produção do conhecimento, estamos nos referindo a uma concepção de processo de ensino e de aprendizagem. Para for-
} 
marmos cidadãos com valores cristãos, com consciência ética e moral, autônomos, críticos, criativos, capazes de encontrar soluções para os desafios da vida, então teremos de pensar o conhecimento como processo de construção contínua e ativa do sujeito.

No que se refere ao ensino, o PPP do CEMS (2012) aponta alguns pontos centrais que implicam a prática da escola. São eles: a) a dimensão holística do conhecimento, no sentido de se trabalhar uma percepção globalizada do mundo, reconhecendo a existência de uma consciência da unidade da vida nas suas diferentes dimensões, manifestações e transformações; b) A interdependência do conhecimento, considerando a especificidade de cada disciplina como organizadora de um campo do conhecimento, mas, ao mesmo tempo, como espaço de interrelações de diálogos com outros saberes e com o universo do qual esses saberes fazem parte; c) O conhecimento como abertura para o improvável e para o inesperado: vivemos num mundo imprevisível, as certezas foram substituídas por novas descobertas, mostrando que nada no universo é fixo e pré-determinado; d) a dimensão histórica do conhecimento: o conhecimento é construído historicamente e é um processo que implica uma relação dialógica entre o objeto, o sujeito e a sua natureza, o meio social e a interrelação entre essas diferentes, mas complementares instâncias.

Acredita-se que, considerando essas diferentes dimensões, a escola é um espaço de formação integral e, nesse sentido, precisa conceber um currículo que valorize as multidimensões do ser humano.

Pode-se dizer que, no PEBM, a aprendizagem é um processo intra e intersubjetivo que produz saberes e identidades, e se fundamenta numa visão como sujeito ativo em complexas interações, interesses e experiência de vida. É um movimento dinâmico de reconstrução do objeto de conhecimento pelo sujeito e de modificação do sujeito pelo objeto, a partir de estratégias próprias de conhecer.

É nesse ponto que se reforça o estudante e seu ofício na Rede Marista:

\footnotetext{
Os estudantes maristas são sujeitos de sua aprendizagem e têm como uma de suas funções articular os saberes construídos no espaço escolar com as experiências vividas, o que resulta na construção de novos conhecimentos e habilidades que os colocam em condições de agir e interagir na sociedade e em suas distintas realidades. (PEBM, 2010, p.74).
}

Nesse sentido, é preciso observar o meio no qual os estudantes estão inseridos. Vivemos em novos tempos, tempos de mudança, e, como educadores, precisamos rever nossas percepções, novos conceitos e novas práticas de sala de aula.

\section{A Metodologia}

Quanto à metodologia, ela precisa considerar os princípios educativos e estar coerente com o tipo de ensino e de aprendizagem propostos pelas instituições: a formação do sujeito autônomo, criativo, lúdico, ético. Isso 
inclui a prática cotidiana voltada para a crença de que todos podem aprender tudo e que ninguém pode ser excluído do processo. Segundo Thurler e Maulini (2012, p. 17), "a escola não se torna equitativa dando a todos os alunos as mesmas chances de fracassar, mas fazendo o melhor para que todos tenham acesso aos saberes de base que têm a obrigação de estudar".

O PPP do CEMS (2012) pontua aspectos importantes da metodologia que sustentam a construção do conhecimento. São eles: a) assimilação ativa: o aluno ativo e envolvido nas atividades escolares; b) Exercitação dos conhecimentos: a possibilidade de ao aluno transferir o que aprendeu para outras situações, para poder resolver problemas existentes; c) Inventividade: no sentido de sair da mera reprodução dos conhecimentos para a transformação dos mesmos. Além disso, o Centro de Ensino Médio Sinodal em seu PPP ainda afirma que metodologicamente o ensino precisa ter ainda as seguintes características: a) possuir sentido e significado; b) ser contextualizado; c) possibilitar o conflito cognitivo; d) desafiar, respeitando as características do nível de desenvolvimento; d) estimular a auto-estima e o autoconceito; e) promover os conhecimentos prévios; f) promover a interdisciplinaridade.

O Projeto Educativo do Brasil Marista nos lembra "há um sonho em construção" (PEBM, 2010, p.35); ou seja, a ressignificação do currículo é uma necessidade pedagógica e pastoral que deve ser atualizada constantemente.
Segundo o PEBM (2010, p.84), "As metodologias pautadas pelo currículo integrado compreendem projetos e sequências didáticas que favorecem a investigação e a problematização". Nos projetos, as atividades são organizadas com o intuito de ressituar a concepções e as práticas educativas buscando compreender e construir respostas possíveis diante do conhecimento e das mudanças sociais. A sequência didática estabelece conexão entre os processos. Nesse sentido, o PEBM (2010, p.84) diz que a sequência didática "compreende o planejamento, desenvolvimento e avaliação de um conjunto de atividades entre si, garantindo a organicidade do processo ensinoaprendizagem", e gera produções coletivas e individuais, e favorece a interdisciplinaridade. Toda a sequência didática possui um contexto real e uma situação problema inserida nessa realidade. No entanto, seu planejamento inicia em uma teia de conhecimento, no qual todos os componentes curriculares que compõem a área de conhecimento registram os conteúdos previstos na Matriz Curricular.

A reestruturação curricular foi sugerida para os colégios da Rede Marista por meio de quatro eixos: perfil docente, avaliação, metodologia e espaçotempo.

\section{A Avaliação da Aprendizagem}

Uma dimensão importante para o acompanhamento da qualidade das aprendizagens produzidas é a avaliação. Diversas são as formas de avaliar, no cotidiano escolar, para agir sobre as dificuldades identificadas e os poten- 
ciais, objetivando reorganizar os processos de ensino aprendizagens.

O PEBM (UMBRASIL, 2010, p.89) afirma que a "ação de avaliar consiste em um processo que deve ser sistemático, compartilhado e demanda assertividade, organização, sensibilidade e criticidade". A avaliação é um processo contínuo, sistemático e cumulativo que identifica, acompanha e analisa as ações educativas e suas repercussões levadas a efeito no estabelecimento de ensino.

Barcelos (1998, p.37) diz: é preciso "descobrir que avaliar é aprender e que avaliar também se aprende e que todos precisam ter o direito de realizar essa aprendizagem". Para Barcelos (1998), a avaliação tem dimensão política e sua principal função é favorecer a melhoria e o crescimento coletivo. Em todos os momentos, estamos aprendendo e ensinando; e sempre com a função de favorecer a melhoria e o crescimento do processo de ensino e aprendizagem, tendo como finalidade principal o acompanhamento contínuo e reflexivo do processo. Como processo de acompanhamento, a avaliação incide do ponto de vista do estudante, possibilita perceber as conquistas obtidas ao longo do processo e compreender a consciência da própria construção do conhecimento.

Segundo PEBM (UMBRASIL, 2010, p.88), "a avaliação baliza, legitima, regula e emancipa o processo de ensino-aprendizagem. Portanto, é fundamental atentarmos às trajetórias de ensino e de aprendizagem e às relações que estão sendo estabelecidas no processo avaliativo".
Para o Centro de Ensino Médio Sinodal, o processo avaliativo deve permear todo o ensino e estar ligado às concepções e as teorias que sustentam a visão de conhecimento e de mundo. Se entendemos que a construção do conhecimento acontece de maneira contínua, inacabada, então a avaliação deve ser vista como um processo que acompanha essa concepção, ou seja, é um processo que possibilita a reflexão o acompanhamento e o redirecionamento da caminhada.

A avaliação, então:

$$
\begin{aligned}
& \text { É uma permanente investigação que } \\
& \text { busca acompanhar e refletir sobre o } \\
& \text { processo de desenvolvimento do } \\
& \text { aluno: para detectar áreas a serem } \\
& \text { melhor trabalhadas e intervir neste } \\
& \text { sentido; para refletir sobre a relação } \\
& \text { entre o planejamento do professor, a } \\
& \text { sua atuação e a do aluno. (CEMS, } \\
& \text { 2012, p.14) }
\end{aligned}
$$

Um professor preocupado que sua prática educacional esteja voltada para a transformação não poderá agir sem pensar e sem planejar. Em sua prática pedagógica, o pressuposto é o diagnóstico contínuo e o planejamento, pois seus estudantes não são iguais, possuem progressos diferenciados. O ato de avaliar não é um julgamento definitivo, mas um indicador, para o professor aprimorar o processo ensino e aprendizagem levando em consideração o ritmo de cada estudante.

Para Haetinger (2010), é preciso pensar a avaliação globalmente, valorizando as experiências e a caminhada de cada indivíduo, buscando avaliações eficazes e reais na educação presencial. As estratégias e instrumen- 
tos avaliativos, em relação aos tempos movimentos de ensinar e aprender, são diversificados, diferenciados, coerentes e adequados de forma a garantir a qualidade da educação. Do ponto de vista docente, as ações pedagógicas, o acompanhamento, a comunicação, a promoção, o feedback individualizado são imprescindíveis, pois estão a serviço do conhecimento e crescimento do estudante.

\section{Função do Professor e a Gestão de Classe}

Thurler e Maulini (2012, p.14) falam sobre o trabalho e a tarefa do professor, dizendo que ele deve empenhar-se para organizar a atividade pedagógica, ou seja, "organizar situações, procedimentos, dispositivos, em suma, as condições coletivas de um trabalho fecundo". O questionamento dos autores reside no trabalho propriamente realizado em sala de aula: nesse caso, a crítica é para a passividade do aluno, enquanto o professor é quem realiza todo o trabalho, o que configura uma inversão que permite que os autores afirmem que "o professor não pode se formar em lugar dos alunos". (THURLER; MAULINI, 2012, p. 14). Os autores dizem que organizar o trabalho de outra maneira, no sentido de reparti-lo, é "envolver os alunos nas práticas intelectuais, no processo de pesquisa, de redação, de comunicação, de seleção e de comparação das informações. É fazê-los entrar ativamente na razão gráfica, não dando uma aula a pegar ou a largar. (THURLER; MAULINI, 2012, p.14).
$\mathrm{Na}$ Rede Marista, para a efetivação de uma prática educativa de qualidade, os professores articulam conhecimentos e experiências construídos em sua formação inicial, em sua formação continuada e no exercício da docência. (UMBRASIL, 2010, p 75).

É relevante que o professor atue como um agente cultural inovador que tem o desafio de atualizar, aprofundar, articular os conhecimentos teóricos e as práticas, de maneira permanente na trajetória profissional.

Segundo o PEBM (UMBRASIL, 2010, p. 76), o ofício do professor, entre outros aspectos, implica:

. educar e evangelizar a partir dos princípios e valores maristas;

. fazer a transposição dos projetos institucionais do Brasil Marista, da Província Marista e da escola marista para a ação docente;

- ser sujeito construtor do currículo da escola, de sua dinâmica e de sua avaliação, a partir de critérios socialmente relevantes à formação do estudante;

- planejar os processos curriculares e os processos de ensinoaprendizagem e mediar a construção do conhecimento dos estudantes, tanto na perspectiva individual como de grupo;

- pesquisar e produzir conhecimentos relevantes ao desenvolvimento de sua carreira e à qualificação da educação e da escola;

- buscar fundamentação teórica e pedagógica relativa à sua área de conhecimento e componente curricular, de modo a atualizar-se continuamente para o exercício de seu ofício;

. desenvolver metodologias e técnicas didáticas adequadas ao processo de ensino-aprendizagem e coerentes 
com o Projeto e as matrizes curriculares do Brasil Marista;

- participar da gestão de processos pedagógicos e da elaboração do projeto pedagógico da escola; . acompanhar e avaliar os processos de aprendizagem dos estudantes;

. utilizar linguagens, mídias e tecnologias adequadas ao processo de construção de conhecimento do estudante; .

. zelar pela imagem e pela marca institucional.

O professor é praticante de pedagogias culturais, pois assume a responsabilidade pela diversidade de temáticas do cotidiano, abordadas na escola, problematizando e ampliando os currículos oficiais, criando teias de significados, percebendo-se como o autor e agente do currículo (UMBRASIL, 2010, p. 75).

O PPP do Centro de Ensino Médio Sinodal, quando fala da concepção de aprendizagem que fundamenta o trabalho na escola - uma concepção na perspectiva construtivista -, fala que o professor assume um papel ativo e comprometido com a aprendizagem do aluno.

A tarefa de ensinar deve compreender sequências didáticas em que o professor se questiona sobre as atividades para que estas contemplem a complexidade da aprendizagem. $\mathrm{O}$ professor precisa considerar os conhecimentos prévios de cada aluno e aluna, para que os conteúdos sejam propostos de maneira significativa e funcional, sejam adequados ao nível de desenvolvimento, que representem um desafio alcançável para cada um, que provoquem um conflito cognitivo e promovam a atividade mental do aluno e da aluna, que estimulem uma atitude fa- vorável em relação à aprendizagem dos novos conteúdos, que proporcionem a auto-estima e o autoconhecimento e que promovam o aprender a aprender. (CEMS, 2012, p.24)

O documento ainda traz que os professores devem considerar que cada aluno é singular, tem seu ritmo de aprendizagem e devem atender a essa diversidade, "valorizando e promovendo situações que garantam aprendizagens para todos" (CEMS, 2012, p. 64). Quanto à relação professor-aluno, no documento, consta que é através dela que se estabelece uma parceria ou não na caminhada da aprendizagem, que o crescimento se dá para todos quando o educador consegue proporcionar um vínculo sadio, de confiança e respeito (PPP do CEMS, p.65).

Quanto aos saberes do professor, o PPP do Centro de Ensino Médio Sinodal (2012, p.74) enfatiza a importância da formação continuada dos professores, dizendo que o professor também aprende e constrói seu conhecimento, aprimorando o seu fazer pedagógico. Para que ele possa aprender, sempre é fundamental que ele possua uma relação com o saber que valorize aquilo que ele aprende.

Se compararmos o que os autores apontam como função do professor e as expectativas que se tem em relação ao trabalho que deverá realizar ao que os Projetos Político Pedagógicos das duas instituições analisadas trazem, podemos afirmar que há muitas convergências, no sentido de reconhecer que é tarefa do professor organizar o projeto pedagógico e responsabilizar-se por ele, que precisa estabelecer 
uma relação de confiança com seu aluno para que ele esteja motivado a aprender, mas que quem precisa trabalhar em sala de aula é o aluno.

\section{O Papel do Educando}

Tanto o PEBM como o PPP do CEMS trazem que os estudantes são sujeitos de sua aprendizagem, pesquisam, leem, escrevem, questionam, analisam buscam novas informações, solucionam problemas, utilizam diferentes linguagens, mídias e tecnologias. Para o PEBM, eles vão além da exigência do professor na produção de conhecimentos e têm com uma das suas funções articular os saberes construídos no espaço escolar com as experiências vividas, o que resulta na construção de novos conhecimentos e habilidades que os colocam em condições de agir e interagir na sociedade e em suas distintas realidades (UMBRASIL, 2010, p 74).

É fundamental para os estudantes saber trabalhar em equipe, construir, agir e pensar no grupo com os colegas.

\section{Tradição e Inovação}

Conforme Zygmunt Bauman (2001, p.232), "vivemos em tempos líquidos, nada foi feito para durar". Mas isso vale também para instituições educacionais? A escola é tida, normalmente, como aquela instituição às quais a inovação chega tarde em que as mudanças acontecem em de forma morosa. Tradição e inovação parecem constituir-se em paradoxos, mas que- remos aqui mostrar que não se trata disso.

Ao definir os termos tradição e inovação, lembramos de uma fala do diretor do Colégio Sinodal, quando questionado em uma conversa sobre o assunto. Ele faz um comparativo, dizendo que a tradição pode ser comparada às lâmpadas dos postes de luz de uma rua: serve para iluminar o caminho do caminhante. Tradição, diz ele, tem a ver com raízes, princípios e valores que perpassam o tempo constituindo-se em fundamentos para a educação que se faz naquela instituição. Ela é, por isso, muito importante. Tudo isso precisa estar em constante avaliação para ver o que realmente continua sendo importante e o que permanece. Em meio a isso, é necessário estar presente a inovação - o conhecimento adequado às necessidades atuais $\mathrm{e}$ perspectivas futuras -, pois nem o humano, nem a realidade são estanques, somos seres caminhantes. Precisamos da luz da tradição e das perspectivas da inovação. A tradição está ali, foi construída ao longo do tempo e é a base do trabalho que uma instituição realiza. A inovação é necessária, pois ela vai melhorando e aperfeiçoando esse trabalho no sentido de validá-lo. O que traz a comprovação da instituição quanto à qualidade do trabalho ali realizado é a tradição que essa instituição tem em fazer bem o seu trabalho, nesse caso a educação. Mas o que consolida o trabalho que a instituição realiza é a sua capacidade de inovar e de se atualizar constantemente.

No nosso entendimento, inovar é fazer a mesma coisa de forma diferente para que esteja mais adaptada a 
um determinado tempo e contexto. Num momento em que a sociedade passa por mudanças em todos os âmbitos, em que a ciência e a tecnologia avançam de maneira significativa, a escola precisa estar preparada para inovar, para repensar concepções sobre educação, pois, conforme Redin (1997, p.49):

Repensar a questão do conhecimento e seus desdobramentos, nas diversas instâncias, nos diferentes espaços e campo em que ele se faz presente, é repensar nossa relação com o mundo, com as pessoas, com os objetos, com as formas de conceber e organizar a vida.

Morin (2013), refletindo sobre os desafios da reforma educacional, afirma que estamos diante da seguinte situação: não podemos modificar a instituição sem antes modificar as mentes, mas o contrário também é verdadeiro, ou seja, não podemos modificar as mentes sem modificar as instituições. Diante desse desafio, trazemos a tradição e a inovação como resultado de uma postura aberta e de escuta que vem assumindo uma relevância progressiva no contexto das melhores instituições, permeando seus projetos estratégicos, a gestão e a docência.

O que faz uma organização tradicional da área da educação se manter em crescimento por tantos anos? Como incorporar o novo sem perder os seus valores, missão e tradição? Como trazer a inovação? Os valores pedagógicos característicos da tradição marista e da tradição do Sinodal servem para iluminar a prática educativa da educação básica e dos centros sociais.

Desde a sua fundação aos dias de hoje, o Instituto Marista celebra seus 202 anos de história, e vem se consolidando, oferecendo uma educação evangelizadora e integral pautada na construção de subjetividades, visando à promoção dos sujeitos em todas as suas dimensões (UMBRASIL, 2010, p. 34). Igualmente o Centro de Ensino Médio Sinodal. São 84 anos fazendo educação de maneira responsável e comprometida, preocupando-se com o pleno desenvolvimento do aluno, seu preparo para o exercício da cidadania, tornando-o um sujeito crítico, participativo e autônomo na construção do seu próprio conhecimento, "assegurando, assim, uma participação consciente e responsável na sociedade, capaz de pensar, criar e agir frente aos desafios do mundo" (PPP do CEMS, p.9).

Essa tradição de trabalho sério, engajado e comprometido fez com que essas instituições se estabelecessem e fez com que houvesse credibilidade no trabalho que desenvolvem. Mas é a inovação que é buscada continuadamente que faz com que essas instituições se mantenham. Essa inovação é perceptível na Missão e nos Valores e Princípios da escola, listados no PPP. Entre os valores e princípios da instituição está a preocupação com a construção do conhecimento, levando em conta a abordagem do novo, conforme se pode ler na missão. A Missão do Centro de Ensino Médio Sinodal é:

Oferecer uma educação que visa à construção do conhecimento, ao de- 
senvolvimento dos valores cristãos, à consciência ético-moral e que valoriza a abordagem do novo, a diversidade cultural, a capacidade para solucionar os desafios da vida, a formação de líderes para a promoção do bem comum. (PPP do CEMS, p. 8).

A Missão dos Colégios e Unidades Sociais da Rede Marista é

Promover uma educação evangelizadora de qualidade, por meio de processos criativos e inovadores, segundo o Carisma Marista, com vistas a formar cidadãos comprometidos com a construção de uma sociedade justa e fraterna. (PEBM, 2015).

Representa a essência e o apelo fundacional da Instituição, também o compromisso social e traduz a razão de ser.

Atualmente, instituições educacionais de qualidade buscam a formação integral do sujeito. E é a educação integral que beneficia um desenvolvimento mais abrangente. Nessa visão de educação, consideradas as infâncias, adolescências, juventudes e os adultos como sujeitos de direitos e o espaço educativo torna-se, assim, um "espaço-tempo" privilegiado para a promoção desses direitos (BONHEMBERGER; MENTGES, 2016, p.16).

Segundo os autores

É justamente esse tipo de constatação que vem justificar, na escola como em outras organizações, modelos alternativos de gestão. Se a competência qualifica o distanciamento entre a prescrição e o trabalho real, se as aprendizagens visadas dependem tanto (se não mais) de iniciativas locais quanto de diretrizes anônimas, se enfim, é mais importante atingir os objetivos que aplicar rigorosamente um procedimento imposto, então é preciso comandar o sistema subordinado as modalidades às finalidades, regulando os meios pelos resultados observados. (THURLER; MAULINI, 2012, p.15)

A escola, para garantir-se no mercado educacional e para continuar a oferecer a qualidade que almeja, precisa constantemente se pensar e repensar, ela precisa se afirmar e reafirmar e recriar, para isso precisa constantemente se construir e reconstruir. $E$ isso é possível não só olhando para o novo, para a inovação, mas sim com o olhar para a referência que a tradição trouxe para as instituições.

\section{Considerações finais}

A leitura do texto A organização do trabalho escolar: pensá-la para fazê-la evoluir, de Monica Gather Thurler e Olivier Maulini, possibilitou que fizéssemos uma leitura crítica também de nossos Projetos Políticos e Pedagógicos, a partir de diversas dimensões. A partir dos elementos elencados para análise dos PPPs das duas instituições consideradas instituições basilares e tradicionais em educação, no sentido de encontrar aproximações, distanciamentos e problematizações, fez com que se pudesse refletir principalmente o papel dessas instituições frente às demandas de inovação e atualização, solicitadas pelas mudanças e 
transformações sociais, políticas, econômicas da contemporaneidade.

A análise mostrou que as escolas analisadas, pertencentes a duas redes privadas de ensino distintas, têm muitas semelhanças em todos os elementos elencados para o estudo. São duas escolas confessionais de educação básica, uma de confissão católica, outra de confissão luterana, que têm arraigados fortemente os princípios de Champagnat (Marista) e de Lutero (Sinodal), são instituições privadas, ou seja, precisam buscar atualizar-se e estar a frente de seu tempo, têm tradição no que se refere ao seu objetivo educacional e ambas estão organizadas de forma a buscar oferecer sempre o melhor aos seus estudantes e demais membros da comunidade escolar no que se refere à aprendizagem, necessitando, para isso, buscar inovar suas práticas educativas e suas formas de gestão. São instituições sérias e comprometidas com seu propósito. Talvez a inovação proposta por Thurler e Maulini (2012) ainda não esteja sendo contemplada pelas escolas, mas entendemos que os espaços e os tempos, ou seja, o contexto, são determinantes para que essas ou outras inovações aconteçam nessas instituições. 


\section{Referências}

BARCELOS, E.S. A avaliação para a cidadania. Curitiba: Editora, 1998.

BAUMAN, Z. Modernidade líquida. Rio de Janeiro: Editora Zahar, 2001.

BONHEMBERGER, M.; MENTGES, M.J. (org.). Educação marista: perspectivas e desafios. São Paulo: FTD, 2016.

Centro de Ensino MÉdio SinOdal. Projeto Político Pedagógico do Centro de Ensino Médio Colégio Sinodal. São Leopoldo, 2012.

CURY, Carlos Roberto Jamil. O direito à educação: um campo de atuação do gestor educacional na escola. Disponível em: <http://escoladegestores.mec.gov.br/site/8biblioteca/pdf/jamilcury.pdf>. Acesso em: 05 out.2018.

HAETINGER, M. Professor Max em revista: criatividade, tecnologia, aprendizagem, avaliação e muitos outros olhares registrados por este educador. Max Haetinger. Curitiba: Editora Melo, 2010.

MORIN, E. A via para o futuro da humanidade. Rio de Janeiro: Bertrand Brasil, 2013.

REDE MARISTA. Plano Estratégico da Rede Marista 2015-2022. Porto Alegre: RS, 2015.

REDIN, Marita Martins. Entrando pela janela...: o des/encantamento da criança pela escola. Dissertação (Mestrado) - Universidade do Vale do Rio dos Sinos, São Leopoldo, RS, 1997.

TEIXEIRA, Evilázio Francisco Borges. Pensando a educação marista com um olhar interdisciplinar. Revista Educação, Porto Alegre, v. 3, n54, p. 617-639, dez.2004.

THURLER, M.G.; MAULINI, O. A organização do trabalho escolar: pensá-la para fazê-la evoluir. In: . (org.). A organização do trabalho escolar: uma oportunidade para repensar a escola. Porto Alegre: Penso, 2012. p. 11-34. Disponível em: http://srvd.grupoa.com.br/uploads/imagensExtra/legado/T/THURLER_Monica_Gath er/A_Organizacao_Trab_Escolar/Liberado/Introducao.pdf. Acesso em: 13 maio 2019. 
UNIÃO MARISTA DO BRASIL (UMBRASIL). Plano Estratégico da Rede Marista 2015-2022. Brasília: UMBRASIL, 2015b.

UNIÃO MARISTA DO BRASIL (UMBRASIL). Projeto Educativo do Brasil Marista: nosso jeito de conceber a educação básica. Brasília, DF: UMBRASIL, 2010.

$O(s)$ autor(es) se responsabiliza $(m)$ pelo conteúdo e opiniões expressos no presente artigo, além disso declara(m) que a pesquisa é original.

Recebido em 11/03/2020

Aprovado em 02/06/2020 